\title{
Photovoltaic for Rural Development: A study of policy impact and scope of market development in South Asian Region
}

\author{
Siddha Mahajan ${ }^{1, *}$, Shirish Garud ${ }^{2}$ \\ ${ }^{1}$ The Energy and Resources Institute, New Delhi, India \\ ${ }^{2}$ Greenergy Renewables Pvt Limited, Mumbai, India \\ * Corresponding author. Tel: +91 1124682100, +91 9873846092, Fax: +91 1124682144, E-mail: \\ siddha.mahajan@teri.res.in
}

\begin{abstract}
Growing energy demand, increase in carbon emissions due to increase in fossil fuels it becomes imperative for developing regions like South Asia to switch to non-conventional sources of energy. Being naturally blessed with the renewable energy resources it becomes easy for these countries to switch. The best resource to be harnessed in the region is the solar energy through Photovoltaic technology. The best part about this technology is its suitability for remote area rural electrification which is the need of hour in the region Access to electricity is essential to bring about equitable economic development in sustainable manner. But, there exist barriers which hold back the development of renewable energy resources. While some countries in this region like India, Sri Lanka and Bangladesh have been able to develop the markets for PV, other countries in the region are yet to develop policies and programs. Financial initiatives as a result of policy push have major role to play in developing the market. Un-electrified rural population being very high in this region, the countries like Nepal, Bhutan Pakistan and Maldives which seeks to develop the market can learn from the success stories of these countries.
\end{abstract}

Keywords: Photovoltaic, South Asia, Policy, Rural development

\section{Introduction}

Energy consumption is an indicator of socio-economic development of the country. With the increasing energy demands coupled with global warming and energy security issues, it becomes imperative for all the countries to switch from conventional carbon based fuels to low carbon sources of energy. This is especially important for the developing countries which are on development path. South Asia is one such region. It is on one hand, one of the major economic hubs of the world, and on the other, is home to a quarter of total world's population, majority of them in rural areas. Major portion of the population of this region still remains devoid of electricity due to infrastructural in-capabilities, high investments required for the development of infrastructure This holds back the development of this part of world. Abundance of sunshine throughout the year makes Photovoltaic (PV) technology a suitable and viable option to provide off-grid and decentralized electricity solutions is a long term cost effective solution that can help in equitable development. It also gives added advantages like rural employment, future energy security, and clean environment. Governments in India, Bangladesh and Sri Lanka have taken several steps ahead to create markets for this technology, through policy intervention in rural areas and there have been successful stories as well. While, Bhutan, Nepal and Maldives are still far behind in the development of market for the technology and can learn from successful stories of neighboring countries to develop a self sustaining market in their regions.

The purpose of this study is to bring out the advantages and impacts of policies on photovoltaic technology through various successful stories that can help in rural development. Also, to understand what are the various financing mechanisms developed for creating market. To achieve this purpose the objectives of this paper are:

- To conduct a cost-benefit analysis of the technology with the conventional sources

- To understand the existing PV deployment in the rural regions of South Asia 
- To learn about the available financial incentives and schemes for its deployment.

- To understand the barriers in market development

\section{South Asia}

\subsection{Current scenario}

The South Asian region, which comprises of Bangladesh, Bhutan, India, Maldives, Nepal, Pakistan, and Sri Lanka ${ }^{1}$ is home to more than 1.5 billion people, reaching almost close to a quarter of the world's population [1]. This geographical region is currently experiencing a rapid growth in energy demand, associated with economic growth and industrialization. Despite, such a growth, there is a huge gap between demand and supply of electricity. Table 1 and figure 1 together summarizes the current scenario. Nearly 613.9 million people in this region are un-electrified in this region (IEA/OECD 2009) consisting mainly of the rural region. This issue, further, is strongly linked to other major issues of poverty, education, and health and hygiene. The electricity production in this region is through coal, petroleum and crude oil imports [2]. Countries like Bangladesh and India do have substantial reserves of natural gas, coal and petroleum, despite that substantial amount is imported for sustaining the commercial and industrial sector for meeting the growing demands. Maldives, on the other hand, rely $100 \%$ on imported refined petroleum. Pakistan, Nepal and Bhutan, derive most of its energy needs through hydro and biomass. Pakistan is still heavily dependent on oil imports. All over in the region, hydro is mainly deployed for commercial power generation; biomass obtained from forests supplements the household energy needs of rural population. This is followed by small hydro and very miniscule amount of solar PV. Conventional fuels that are common among rural population are kerosene and diesel that are offered at highly subsidized rates. A study by UNDP shows that this region has medium to high Oil Price Vulnerability Index (OPVI) ${ }^{2}$ point for all the countries. It has been found that the divergence of large amount of national investments towards the fuel imports side-lines the social development. Also, huge dependence on the foreign oil imports leads to insecurity of energy.

Table 1: Summary of South Asian countries energy scenario[3,4,5,6,7]

\begin{tabular}{cccccc}
\hline Country & $\begin{array}{c}\text { Land area } \\
\text { (sq. km) }\end{array}$ & $\begin{array}{c}\text { Total } \\
\text { Population } \\
\text { (million) }\end{array}$ & $\begin{array}{c}\text { Energy } \\
\text { production } \\
\text { (Mtoe) }\end{array}$ & $\begin{array}{c}\text { Population } \\
\text { without electricity } \\
\text { (millions) }\end{array}$ & OPVI Index \\
\hline Bangladesh & $1,47,570$ & 158 & 21.26 & 95.7 & High \\
\hline Bhutan & 38,394 & 0.6 & 0.6804 & NA & Medium \\
\hline India & $32,87,263$ & 1123 & 450.92 & 403.7 & Medium \\
\hline Maldives & $8,59,000$ & 0.3 & NA & NA & High \\
\hline Nepal & $1,47,181$ & 28 & 8.53 & 16.5 & High \\
\hline Pakistan & $8,03,950$ & 162 & 63.64 & 68 & High \\
\hline Sri Lanka & 65,610 & 19 & 5.08 & 4.7 & High \\
\hline
\end{tabular}

\subsection{Solar energy deployment}

South Asia being a tropical region is abundantly rich in solar energy, receiving an average solar radiation of $4-4.9 \mathrm{kWh} / \mathrm{m}^{2}$ [8]. The most important contribution of this source is in the decentralised and off-grid power supply to the remote rural areas where grid connectivity is not possible. This will not only contribute to the rural development but also the equitable

\footnotetext{
${ }^{1}$ Afghanistan, though a part of South Asia has not been considered due to unreliability of data

${ }^{2}$ Oil price vulnerability index (OPVI). It is calculated with the help of three indices economic strength, economic of performance and economic growth with low share of oil
} 
social and economic development of the rural parts, thus contributing to the overall development of the country as a whole.

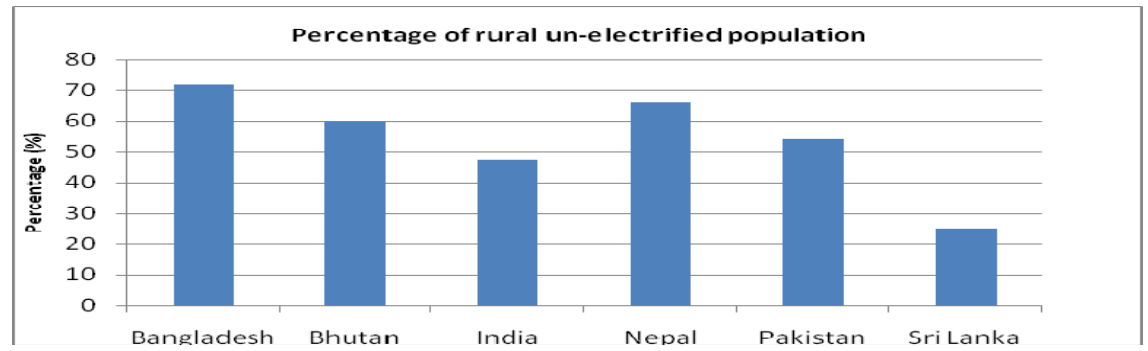

Fig. 1: Graph showing the total un-electrified population in South Asia. Data for Maldives is unavailable [9]

\subsection{Photovoltaic technology}

Photovoltaic (PV) is the technology through which the solar power can be harnessed. Photovoltaic is the array of cells, commonly known as solar cells, which convert solar energy into electricity. The commonly used end use applications of solar PV in rural areas are Solar Home Lighting Systems/Solar Home Systems, Solar Lanterns, Solar Street Lighting Systems, Solar PV Water Pumping system. These applications are put in use for various purposes like residential, rural communities, schools and hospitals electrification, for micro enterprises, water pumping, signalling remote telecommunication, captive power generation, back up power generation, urban applications, highway lightings and many more.

\subsection{Choice of Solar PV as preferred technology}

Harnessing of this resource is suggested above other resources because of the reliability, modularity and free and easy availability of the resource in the region, unlike wind, biomass and hydro energy which are highly site specific. The two most important benefits are:

1. It can be used for rural electrification in remote areas. This is the most potential reason for the South Asian countries to adopt this technology.

2. The fuel cost is zero and no fuel supply linkages are required as in biomass [Refer to Table 1].

This reduces the dependence on the fossil fuels and the large drain of money due to imports of fuels. Besides these, it is a silent process of energy generation and the installation of the technology does not require large space. In case of roof-tops it uses the unused spaces on the roof. It is easy to install and maintain; produced and consumed at the same place so no translocation charges. PV modules can be added to increase the capacity as needs grow.

\section{Methodology}

Literature study was done firstly to understand the basic energy scenario in each country through primary and secondary research. Stakeholder discussions and sector knowledge of the experts was also taken as secondary research that provided the dynamic of the sector. Open ended structured questionnaires were prepared and were mailed to the organizational heads in different countries. Questionnaires prepared for the countries were based on the current situation and the literature survey done during previous research. Two sets of questionnaires were prepared. One set was for India, Sri Lanka and Bangladesh and another set was for Pakistan, Bhutan, Maldives and Nepal. 13 respondents were mailed the questionnaire, out of which only three responded. These respondents belonged to Nepal, Bangladesh and Sri Lanka. Due to weak responses to the questionnaire the analysis for Bhutan, Pakistan and Maldives was based on the data collected during literature survey and stakeholder consultation. 
The values taken for conducting cost benefit analysis has been mainly taken from the Indian market since the facts say that the market is most developed in India. The calculations are based on the study done by International Energy Studies in 2004 [10]. The results obtained would be used as a representative data for the region to understand the cost and benefits of the technology. The calculations have been carried out in USD with the conversion factor of 44.45, as per the currency conversion rate in April, 2010.

Thus, results produced are primarily based on the articles, reports, research papers, publications, stakeholder discussions and sector knowledge of experts. Various international conference presentations by national experts of different countries were also used in understanding, documenting, analyzing the PV market. The results have been produced in both quantitative and qualitative form.

\section{Results and Discussions}

\subsection{Cost-benefit analysis of the technology with the conventional sources}

The Cost Benefit Analysis (CBA) has been carried out between the off-grid solar PV rooftop and conventional power plants (thermal power plant, diesel and natural gas power plant) that would be providing the electricity to the un-electrified region through grid connection.

\subsubsection{Total Cost of generation}

Figure 2 compares the total cost of generation (TCoG) from four different fuel plants. TCoG for off-grid PV is found to be greatest among the four i.e. $\$ 0.4719 / \mathrm{kWh}$ followed by Diesel power generation and natural gas. It has come least for the coal generated power i.e. \$ 0.0509/kWh. Higher TCoG of solar PV is mainly because of high capital cost of the technology.

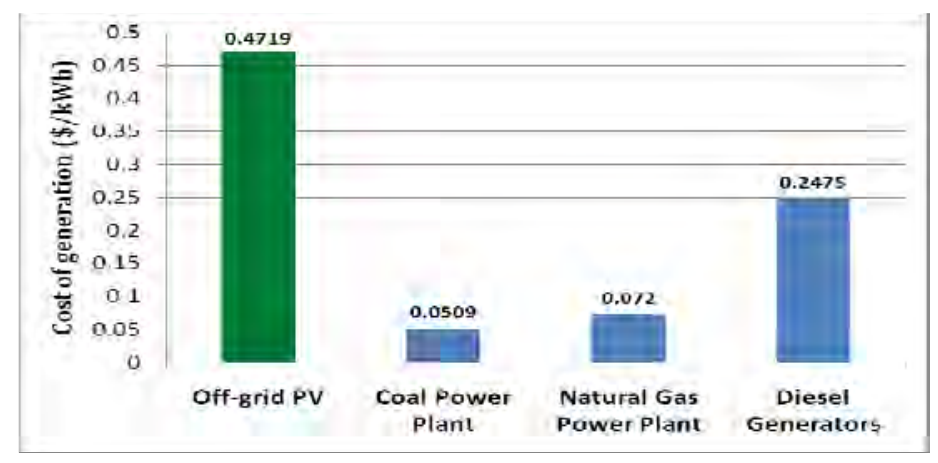

Fig. 2: Comparison of cost of electricity generation profit

\subsection{2. $\quad$ Net Profits}

Figure 3 and 4 compares the net profits on the cost of generation for electricity derived from the conventional and PV power plants before and after internalising the environmental cost, respectively. The costs have been calculated over the useful life of the plants. The useful life of Off-grid PV, coal power plant and natural gas power plant is 25 yrs [11]. It is found that that net profits over the remains positive in all the cases but it is higher by investing in off grid solar PV. Long-term profits further decrease in case of investments in conventional plants when environmental cost is internalized. Diesel power plant could not be assessed due to the lack of data but it can be understood with the combustion properties of diesel the NPV tends to come down if environmental cost in internalized. 


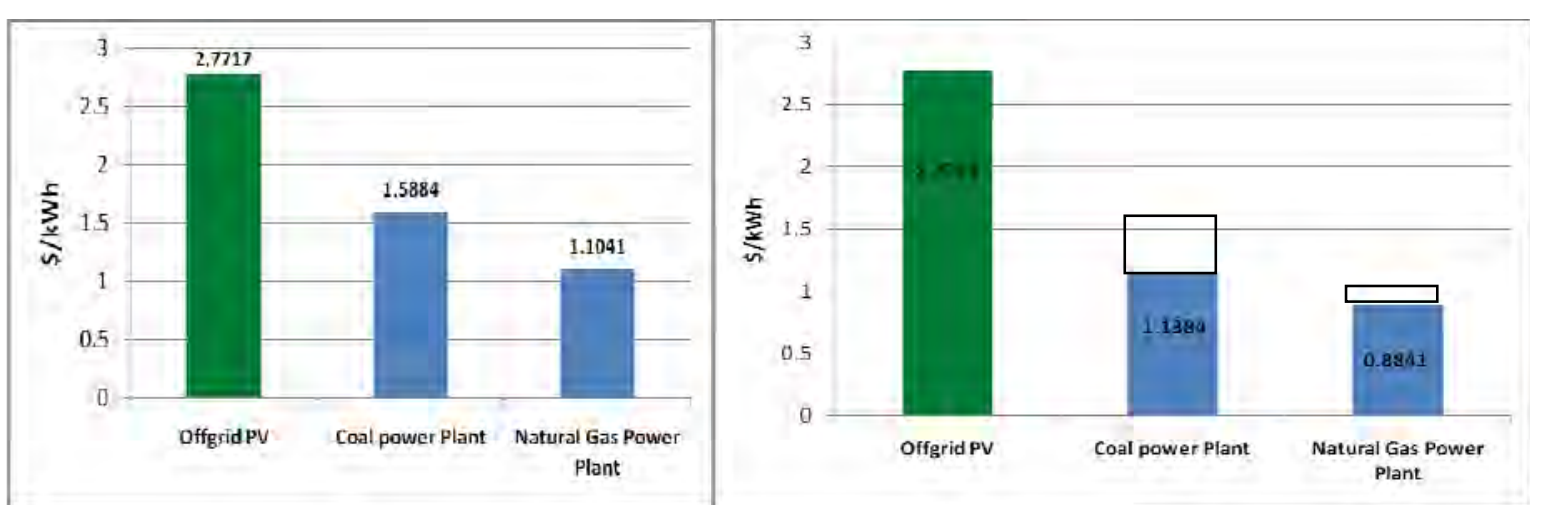

Fig. 3: Net profit before internalizing environment cost; Fig 4: Net Profit after internalising the environment cost

\subsubsection{Net present value}

Figure 5 shows that the net returns of today's investment in the PV project. Results show that investments in PV deployment would fetch greater returns than investments today in conventional plants.

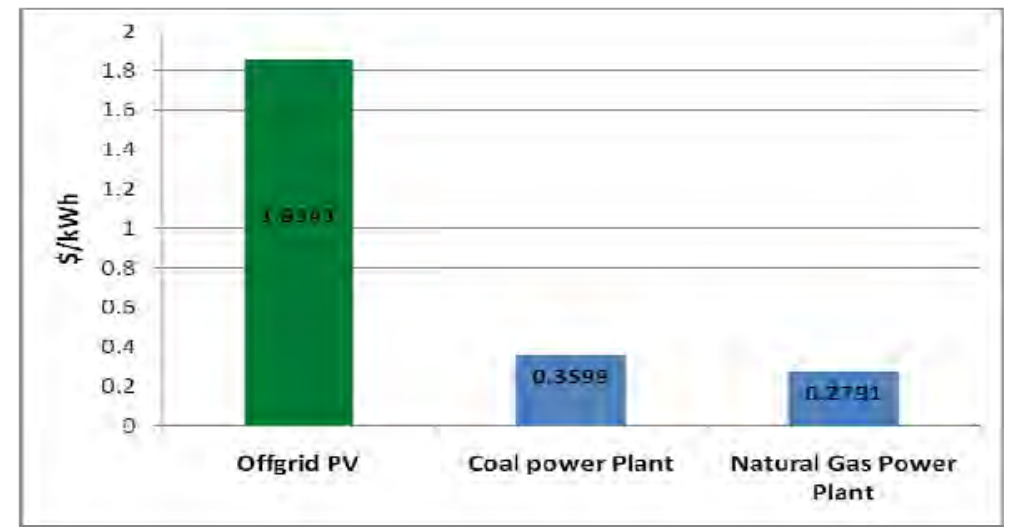

Fig. 5: NPV of various power generators

\subsection{PV deployment}

Table 3 and figure 6 are the summary of the PV installations done in South Asia. Out of all the PV off-grid installations, the most popular end use application is the Solar Home lighting Systems (SHSs). It has been installed in almost all the countries in South Asia. It is followed by the distribution of solar pumps. It is used in India, Bangladesh and Nepal. It is followed by solar lanterns distributed mainly in the rural areas which are un-electrified. Street lighting systems which has found more urban application is in use in India. In Bangladesh, it is still in the discussion phase. Over the years, with the developing market the number of installations has also increased. Thus it can be concluded from the above table and graph that PV market is most developed in India, followed by Bangladesh and Sri Lanka

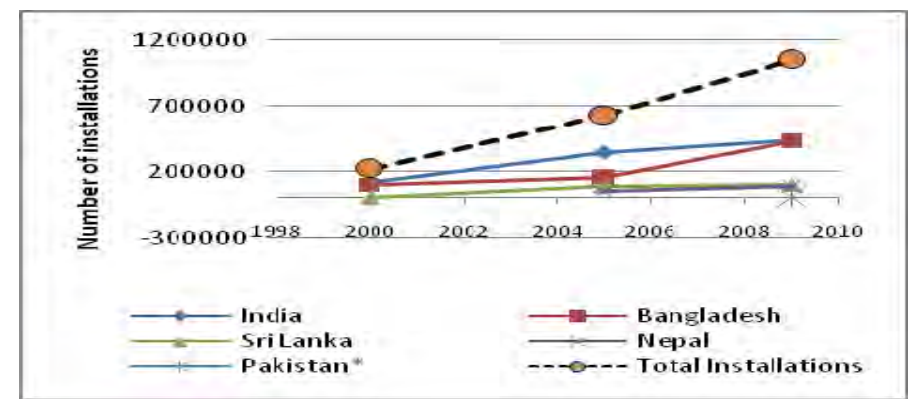


Fig 6: Total SHS installations in South Asia

Table 3: Various end use applications of PV

\begin{tabular}{|l|l|l|l|l|}
\hline Country & $\begin{array}{l}\text { Solar Home lighting } \\
\text { Systems (SHS) }\end{array}$ & Solar Lanterns & $\begin{array}{l}\text { Solar Street lighting } \\
\text { systems }\end{array}$ & Solar Pumps \\
\hline Bangladesh & & & & \\
\hline India & & & & \\
\hline Sri Lanka & & & & \\
\hline Pakistan & & & & \\
\hline Bhutan & Nepal & & & \\
\hline Maldives & & & \\
\hline
\end{tabular}

\subsection{Financial incentives available}

Table 4 summarises various financial incentives offered in the South Asia region. The PV market set up in South Asia so far has been set up mainly in three countries: India, Sri Lanka and Bangladesh.Although, the market is small yet, it is growing up. The majority of the market share is that of off-grid installations. The two main financial mechanisms which have been effective in this market segments are :

Table 4: Off-grid financial schemes for PV

\begin{tabular}{|c|c|c|c|}
\hline \multirow{2}{*}{ Country } & \multicolumn{3}{|c|}{ Off-grid Schemes } \\
\cline { 2 - 4 } & Micro credit System & Capital Subsidy & Interest Subsidy \\
\hline Bangladesh & & & \\
\hline India & & & \\
\hline Sri Lanka & & & \\
\hline Nepal & & & \\
\hline Bhutan & & & \\
\hline Pakistan & & \multicolumn{2}{|c|}{ Data unavailable } \\
\hline Maldives & & & \\
\hline Practiced \\
\hline
\end{tabular}

Micro-credit System: This is mainly practiced in Bangladesh and has been successful in creating the rural market in the country. A community participation initiative taken on the basis of trust to make repayments of loans has been very successful in developing rural sector of the country (See figure 7). Initiative taken by the Grameen Bank in Bangladesh has helped the rural market to grow rapidly. It is interesting to note that today the villagers have $90 \%$ shareholding whereas; the government has $10 \%$ share holdings.

Capital Subsidy: This financial mechanism is practiced in India and Sri Lanka (See figure 8). While in case of India the subsidy given is supported by the Government, in Sri Lanka the subsidy given is supported mainly by the international support. The international support given to Sri Lanka for the promotion of Solar Home Lighting Systems had actually crossed the target set for installations and has been a major reason of success in the rural sector.

The above two financial models have been succesful in revolutionising SHSs in the respective countries and creating the market. Soft loans have also been extended to the consumers for achieving the targets of SHSs installations in Sri Lanka and India. Soft loan scheme is a interest subsidy scheme where interest charged on loan is lower than the prevailing market interest rate. It was introduced in India in the year 2002-2003 for financing the purchase of 
solar photovoltaic systems by various categories of users. This is slowly replacing the upfront capital subsidy schemes which need huge budgetary support from the government.

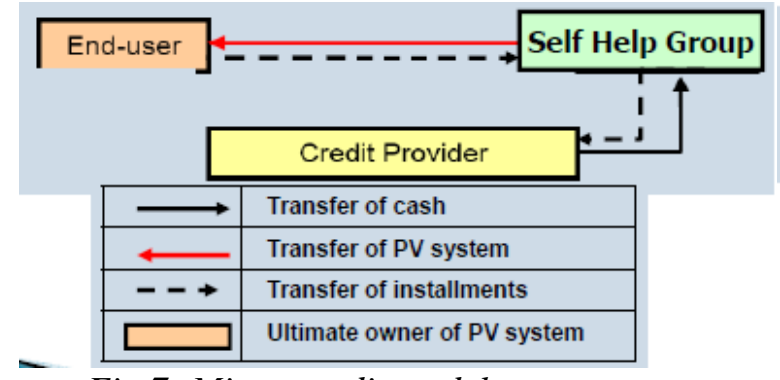

Fig 7: Micro-credit model

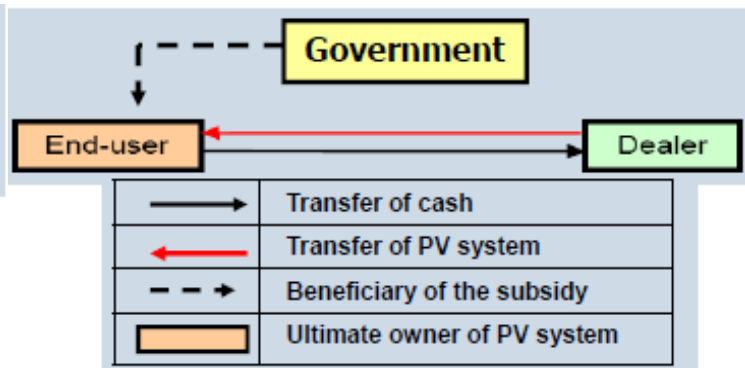

Fig 8: Capital Subsidy Model

\subsection{Barriers}

Table 5 summarises various barriers country wise. The two common barriers in the promotion of PV market in the South Asian countries are lack of R\&D sector focussed on solar energy development and the funds availability. Also the people awareness and the availability of technologies are other barriers which hold back the growth of the market. Political inconsistency is one of the prime concerns of the funding given by the international funding agencies. But, with a successful example of Bangladesh one can learn that with more of people's willingness and interest in taking initiatives market could be created. Lack of information about the resource, needs, appropriate technologies are also major issues in developing the markets especially in Bhutan, Nepal, Maldives and Pakistan. Lack of suitable financing schemes has also held back the development of PV market in countries like Bhutan, Maldives and Pakistan.

Table 5: Barriers in various countries for PV

\begin{tabular}{|l|l|l|l|l|l|l|l|}
\hline Barriers & Bangladesh & Bhutan & India & Maldives & Nepal & Pakistan & Sri Lanka \\
\hline Financing schemes & & & & & & & \\
\hline R\&D & & & & & & & \\
\hline Lack of Information & & & & & & & \\
\hline Funds availability & & & & & & & \\
\hline $\begin{array}{l}\text { Institutional } \\
\text { Framework }\end{array}$ & & & & & & & \\
\hline Political instability & & & & & & & \\
\hline
\end{tabular}

In all these countries though the PV technology is used for the off- grid power generation yet, either the contribution compared to grid power is miniscule or nearly zero. SHSs have found easy way in the market because of affordable incentive schemes and favourable policy environment. In Bangladesh because of its properties like modularity, easy maintenance and with Self Help Group (SHG) practice in Bangladesh, the banks have been ready to provide loans for installation. The main policy push comes from the government, thus government plays a major role in penetration of the technology. The financial schemes to create and support the off-grid market like capital subsidy in India and Sri Lanka and microcredit system of Bangladesh made it easy for the rural consumers to meet their power demands and easy down payments have been supported by government. Central funding is still an issue as many countries are not able to afford the same. Besides, it is also seen the government does not allocate the funds for the development of solar energy technology and its harnessing. 


\section{Conclusion and Recommendation}

The policies initiatives for flexible and easy flow of cash have a major role to play in the proliferation of PV technology into the market, especially when the market development is in the nascent stage and is dominated by the rural population. While in case of India and Sri Lanka, capital subsidy and soft loans succeeded to generate the market for Solar Home lighting installations, micro-credit system model succeeded in Bangladesh to develop market among rural sector. This has also helped in generating rural employment and averting poverty by promoting cottage industries. This, keeping into consideration the large un-electrified population, and increase in PV market through installations of SHS in India, Bangladesh and Sri Lanka, it is very much possible for other countries in South Asia to learn from the neighboring countries and work towards development of market. There are several disadvantages considered for the technology like it cannot be used during cloudy and rainy seasons and that its output is not comparable to the conventional sources but it is the government through policy should encourage capacity building and R \& D to overcome barriers. Also, at the initial stage government should also provide lucrative offers to bank to promote adoption of PV at easy interest rates. This would not only help in building rural market but would also boost rural employment and avert other social issues.

\section{References}

[1] South Asia Environment Outlook 2009 http://www.roap.unep.org/publications/SAEO\%202009.pdf [Accessed 12 November 2010]

[2] United Nations Development Programme, 2007. Overcoming vulnerability to rising oil prices options for Asia and the Pacific, Thailand.

[3] Energy and the Poverty in the Maldives, UNDP Report, Challenges and the way forward, 2007

[4] Development Effectiveness Brief Report of Bhutan, Asian development Bank

[5] Overview of Energy policies in Bhutan, Department of Energy, Ministry of Economic Affairs, RGoB March 2009

[6] International Energy Outlook, International Energy Agency, 2009

[7] http://tonto.eia.doe.gov/cfapps/ipdbproject/IEDIndex3.cfm?tid=2\&pid=2\&aid=2 [Accessed 22 February 2010]

[8] http://www.oksolar.com/abctech/solar-radiation.htm

[9] http://www.worldenergyoutlook.org/database_electricity/electricity_access_database.htm [Accessed 22 February 2010]

[10] Sayathe, J. \& Phadke, A., 2004. Cost and carbon emissions of coal and combined cycle power plants in India: Implications for costs of climate mitigation projects in a nascent market, International Energy Studies, Berkeley, USA

[11] CERC (Terms and Conditions of Tariff) Regulations, 2009

[12]Summary report of the study " Post-Clearance Environment impacts and Cost benefit analysis for Power Generation in India” Conducted by National Environment Engineering Institute (2006) Available at: http://www.mospi.gov.in/research_studies_post_clearance.htm 